\title{
Penilaian Kualitas Visual Lanskap The Bay Villas Resort, Tanjung Lesung - Banten
}

\author{
Intan Fadhilah Birrul Walidain ${ }^{{ }^{*}}$, Rully Besari Budiyanti ${ }^{1}$, Silia Yuslim ${ }^{1}$ \\ 1. Prodi Arsitektur Lanskap, Universitas Trisakti, Jl. Kyai Tapa No.1 Grogol, Jakarta, Indonesia \\ *E-mail: intanfadhilahbw@gmail.com
}

\begin{abstract}
Visual quality assessment of The Bay Villas Resort, Tanjung Lesung Banten. The Bay Villas Resort is a recreational area located in Tanjung Lesung, Banten, and is equipped with facilities to stay overnight. The Bay Villas Resort has beautiful natural and visual resource potential. The beach is clean and beautiful, overlooking the Sunda Strait and leading to Mount Krakatau. The problem is that the existing visual potential has not been utilized optimally. This can be seen from the unavailability of facilities for outdoor activities that take advantage of this potential. This study uses qualitative methods with research instruments in the form of observation followed by visual potential assessment with assessment methods. Data analysis used interval classes which were then classified according to their visual quality. This study aims to identify the visual potential as the basis for the development of the landscape of The Bay Villas Resort according to the characteristics and visual quality. The results of the research in the form of landscape visual quality which are classified into high, medium, and low landscape visual qualities will be useful as a basis for the placement of facilities in further landscape development.
\end{abstract}

Keywords: Assessment method, Visual assessment, Visual Quality

\section{Pendahuluan}

Tanjung Lesung merupakan Kawasan Ekonomi Khusus (KEK) yang dikembangkan menjadi kawasan wisata International karena memiliki terumbu karang yang indah dan pantai dengan pasir putih yang bersih. Salah satu destinasi wisata di sana adalah The Bay Villas Resort yang terletak di Tanjung Lesung, Tanjung Jaya, Kecamatan Panimbang, Kabupaten Pandeglang, Provinsi Banten. Lokasi The Bay Villas Resort menghadap Selat Sunda dan secara langsung mengarah ke Gunung Krakatau, dengan fasilitas berupa dive center, villa, beach hotel, dan resort. Dari gambaran tersebut, lanskap kawasan The Bay Villas Resort dimaknai sebagai Landscape as Aesthetic, yaitu lanskap yang dipenuhi oleh beragam-keindahan visual dari bentukan-bentukan khas lanskap (Motloch, 1991).

Sebagai destinasi wisata, The Bay Villas Resort, belum memanfaatkan potensi visual yang ada secara optimal. Fasilitas bagi pengunjung untuk melakukan berekreasi di ruang luar belum dikembangkan, terutama fasilitas yang memanfaatkan potensi visual yang ada. Pengunjung resort belum dapat menikmatinya secara maksimal. Untuk itu, perlu dilakukan penilaian terhadap potensi visual agar dapat dimanfaatkan secara optimal bagi penempatan fasilitas rekreasi bagi pengunjung. Penilaian dilakukan pada kualitas visual lanskap menggunakan Assesment Method untuk mengungkapkan dan mendeskripsikan unsur-unsur atau dimensi kualitatif dari suatu kualitas lanskap (Firmansyah, 2011). Tujuan dari penelitian ini adalah mengklasifikasikan potensi visual berdasarkan penilaian kualitas visual (kualitas visual yang tinggi, sedang dan rendah) dan memetakannya pada tapak. Ini karena pemanfaatan visual lanskap dalam penempatan fasilitas dapat meningkatkan pengunjung suatu kawasan sehingga dapat memberikan nilai ekonomi pada kawasan (Budiyono \& Soelistyari, 2016). Hasil penelitian ini diharapkan dapat dimanfaatklan bagi pengembangan rancangan lanskap The Bay Villas Resort di kemudian hari.

\section{Metode}

\subsection{Lokasi dan Waktu Penelitian}

Penelitian dilakukan di The Bay Villas Resort yang terletak di Tanjung Lesung, Tanjung Jaya, Kecamatan Panimbang, Kabupaten Pandeglang, Provinsi Banten dengan luas 9,3 ha. Dengan waktu 
penelitian selama 6 bulan yaitu bulan maret-agustus 2021. Batas tapak di sisi Timur yaitu Selat Sunda, bagian sisi Selatan Jl. Tanjung Lesung Raya, sisi Barat Kalica Villas dan sisi Utara Beach Club (gambar 1).

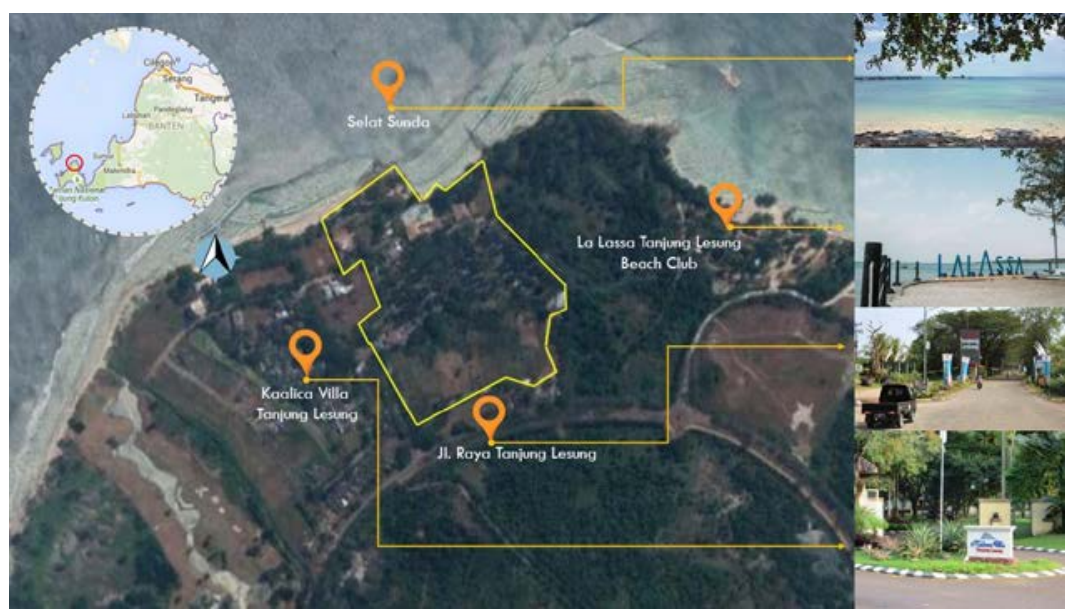

Gambar 1. Batasan tapak

(Sumber: Google Earth, 2021)

\subsection{Metode Penelitian}

Penelitian ini menggunakan metode penelitian kualitatif, dengan pendekatan studi kasus. Teknik pengumpulan data dilakukan dengan menggunakan metode survey dan observasi. Penilaian visual lanskap dilakukan dengan menggunakan metode assessment deskriptif. Penggunaan metode penilaian ini dilakukan untuk mengungkapkan dan mendeskripsikan unsur-unsur atau dimensi kualitatif dari suatu kualitas lanskap (Firmansyah, 2011). Tahap pertama dari metode tersebut adalah melakukan pemilihan dan penetapan sampling scene (view point) berupa foto yang akan digunakan sebagai pengamatan dalam menilai kualitas visual. View point merupakan tempat-tempat yang menawarkan pemandangan yang indah atau khas dengan jarak pandang tertentu (Krisantia \& Rabindra, 2014). View point diambil berdasarkan pertimbangan lokasi pengamatan, kegiatan pengamatan, dan tempat pengamatan proyek yang potensial (Smardon, 1988).

Tahap berikutnya, penilaian visual lanskap berdasarkan sistem rating yang dilakukan oleh peneliti. Penilaian visual dilakukan berdasarkan variabel yang diambil yaitu kualitas visual dan karakter visual (Tabel 1). Kemudaian, tahap selanjutnya adalah analisis visual, dilakukan untuk menghasilkan klasifikasi kualitas visual tinggi, sedang dan rendah. Penilaian yang dilakukan menggunakan kategori berjumlah 3 , yaitu tinggi = 3 , sedang $=2$, dan rendah $=1$. Pada analisis visual menggunakan interval class dengan rumus:

$$
\text { Panjang Interval }=\frac{H-L}{n \text { kategori }}
$$

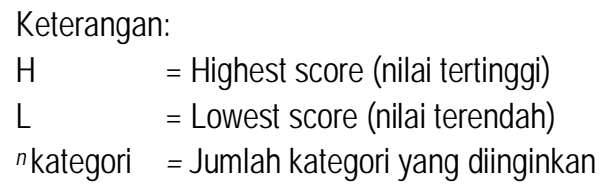

Tabel 1. Kriteria Penilaian Visual Lanskap

\begin{tabular}{llrrl}
\hline NO & PERNYATAAN & $\begin{array}{l}\text { KRITERIA } \\
\text { PENILAIAN }\end{array}$ & $\begin{array}{c}\text { SKOR } \\
\text { PENILAIAN }\end{array}$ & KETERANGAN \\
\hline KARAKTER VISUAL & Tidak tersedia & 1 & $\begin{array}{l}\text { Tidak tersedia } \\
\text { karakterstik alami }\end{array}$ \\
& $\begin{array}{llll}\text { Natural } \\
\text { Setting }\end{array}$ & $\begin{array}{l}\text { Tersedianya karaktersitik alami sepertiCukup tersedia } \\
\text { gunung/ laut/ pantai }\end{array}$ & 2 & $\begin{array}{l}\text { Tersedia } 1 \text { atau 2 jenis } \\
\text { karaktersitik alami }\end{array}$ \\
& Sangat tersedia & 3 & $\begin{array}{l}\text { Tersedia 3 jenis } \\
\text { karakteristik alami }\end{array}$
\end{tabular}




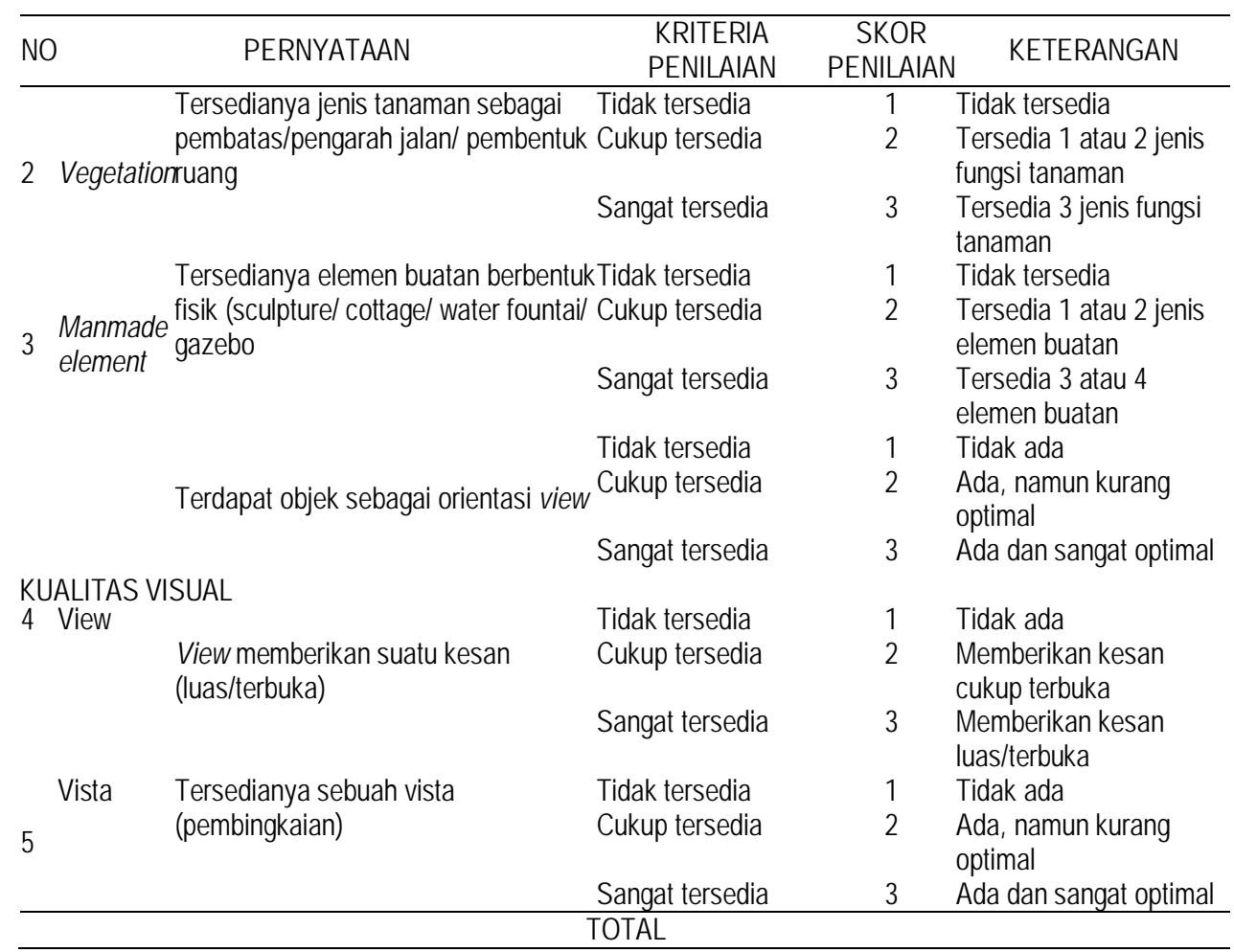

Berdasarkan penilaian visual yang akan dilakukan, score tertinggi adalah 18 dan score terendah adalah 6 . Jumlah kategori yang diinginkan adalah 3 (tinggi, sedang, dan rendah). Berdasarakan rumus maka diperoleh panjang interval adalah 4. Dari perhitungan tersebut, maka ditentukan interval dan kategorinya seperti yang terlihat pada tabel 2.

Tabel 2. Kategori Penilaian dan Panjang Interval

\begin{tabular}{clc}
\hline NO & \multicolumn{1}{c}{ INTERVAL } & KATEGORI \\
\hline 1 & Tinggi & $14-8$ \\
2 & Sedang & $10-13$ \\
3 & Rendah & $6-9$ \\
\hline
\end{tabular}

\section{Hasil dan Pembahasan}

Berdasarkan penilaian visual lanskap dapat diklasifikasikan kualitas visual dan karakter visual yang ada pada objek penelitian. Berdasarkan kriteria penilaian, diperoleh data terkait kualitas visual dan karakter visual yang dapat dimanfaatkan untuk pengembangan rancangan lanskap The Bay Villas Resort.

Hasil pengamatan yang dilakukan berdasarkan lokasi, kegiatan, dan tempat pengamatan proyek yang potensial dihasilkan 6 buah view point. Enam buah view point ditentukan berdasarkan perwakilan dari setiap zona yang ada pada tapak, pemilihan view point berdasarkan pertimbangan dari lokasi, kegiatan dan tempat pengamatan yang potensial (Smardon, 1988). Penilaian dilakukan pada view point yang telah ditetapkan. Penilaian dilakukan dengan sistem rating. View point sebagai titik penilaian visual lanskap pada penelitian ini, terdapat pada gambar 2. Enam View point yang telah ditentukan adalah restaurant dan pool area, beach area, lawn area, children playground area, welcome area dan cottage area. View point yang telah terpilih kemudian dinilai kualitas visualnya. Pada penilaian visual lanskap variabel yang dinilai adalah karakter visual dan kualitas visual, berikut merupakan penilaian visual pada The Bay Villas Resort. 


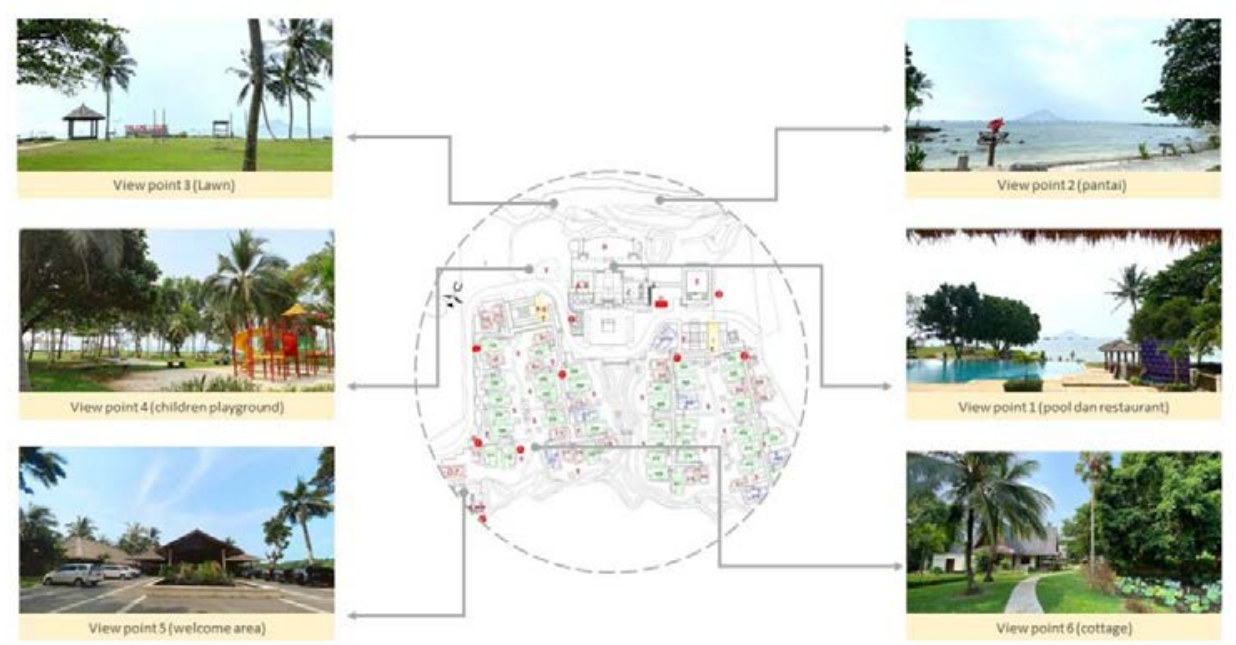

Gambar 2. Penentuan Titik View Point pada Masterplan The Bay Villas Resort

Sumber: Dokumen Pribadi Peneliti, 2021

View point 1 (Restaurant dan Pool Area), view point 2 (Beach Area), dan view point 3 (Lawn Area) diambil pada zona rekreasi yang merupakan area pantai dan menghadap langsung kearah gunung krakatau, pada zona ini kegiatan yang dilakukan adalah menikmati view dan merupakan titik yang potensial untuk menikmati potensi visual pada tapak. View point 4 (Children Playground Area) dan view point 6 (Cottage Area) diambil pada zona cottage, karna berada di zona penginapan maka kegiatan yang dilakukan cenderung pasif yaitu menginap dan bersantai. Untuk view point 5 (Welcome Area) diambil di zona penerima kegiatan yang ada adalah keluar masuk kendaraan dan pengguna tapak. Berikut penilaian kualitas visual yang dilakukan di tiap view point:
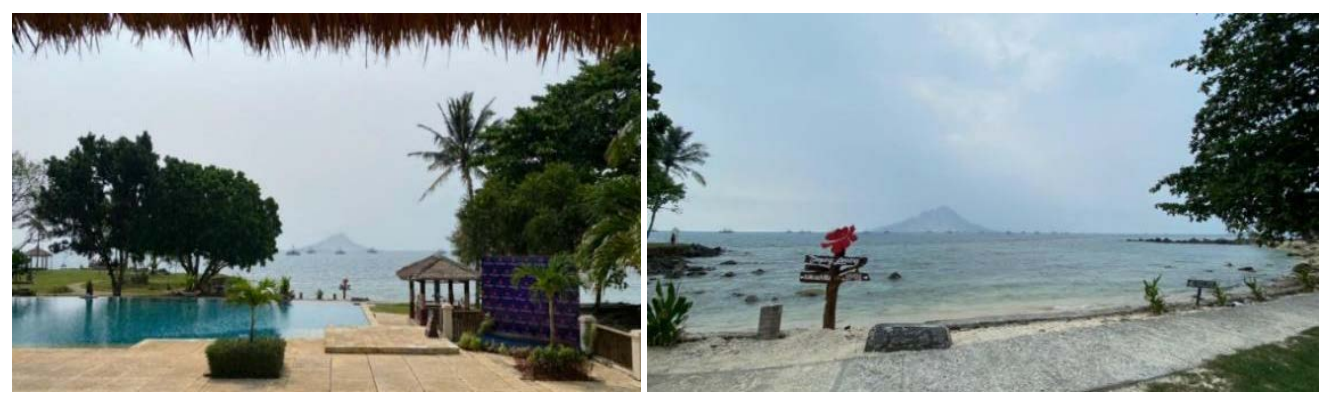

Gambar 3. View Point 1 (Restaurant and Pool area) dan View Point 2 (Beach Area) Sumber: Dokumen Pribadi Peneliti, 2021

View point 1 (restaurant and pool area) dan view point 2 (beach area) berada di zona rekreasi pantai yang menghadap langsung kearah gunung krakatau. Berdasarkan potensi visual yang ada dilakukan penilaian visual lanskap pada view point 1 dan view point 2 yang dapat dilihat pada tabel 3 dan tabel 4 .

Tabel 3. Penilaian View Point 1 (Restaurant and Pool Area)

\begin{tabular}{|c|c|c|c|c|c|c|}
\hline \multirow{2}{*}{\multicolumn{3}{|c|}{$\begin{array}{ll}\text { No } & \text { Pernyataan } \\
\text { KARAKTER VISUAL }\end{array}$}} & \multirow[t]{2}{*}{ Kriteria Penilaian } & \multirow[t]{2}{*}{ Skor } & \multirow[t]{2}{*}{ Penilaian } & \multirow[t]{2}{*}{ Keterangan } \\
\hline & & & & & & \\
\hline \multirow{3}{*}{1} & \multirow{3}{*}{$\begin{array}{l}\text { Natural } \\
\text { Setting }\end{array}$} & \multirow{3}{*}{$\begin{array}{l}\text { Tersedianya karaktersitik alami } \\
\text { seperti gunung/ laut/ pantai }\end{array}$} & Tidak tersedia & 1 & \multirow{3}{*}{3} & Tidak tersedia karakterstik alami \\
\hline & & & Cukup tersedia & 2 & & $\begin{array}{l}\text { Tersedia } 1 \text { atau } 2 \text { jenis karaktersitik } \\
\text { alami }\end{array}$ \\
\hline & & & Sangat tersedia & 3 & & Tersedia 3 jenis karakteristik alami \\
\hline \multirow{3}{*}{2} & \multirow{3}{*}{ Vegetation } & \multirow{3}{*}{$\begin{array}{l}\text { Tersedianya jenis tanaman } \\
\text { sebagai pembatas/pengarah } \\
\text { jalan/ pembentuk ruang }\end{array}$} & Tidak tersedia & 1 & & Tidak tersedia \\
\hline & & & Cukup tersedia & 2 & 2 & $\begin{array}{l}\text { Tersedia } 1 \text { atau } 2 \text { jenis fungsi } \\
\text { tanaman }\end{array}$ \\
\hline & & & Sangat tersedia & 3 & & Tersedia 3 jenis fungsi tanaman \\
\hline \multirow[b]{2}{*}{3} & \multirow[b]{2}{*}{$\begin{array}{l}\text { Manmade } \\
\text { element }\end{array}$} & \multirow{2}{*}{$\begin{array}{l}\text { Tersedianya elemen buatan } \\
\text { berbentuk fisik (sculpture/ } \\
\text { cottage/ water fountai/ gazebo }\end{array}$} & Tidak tersedia & 1 & & Tidak tersedia \\
\hline & & & Cukup tersedia & 2 & 3 & $\begin{array}{l}\text { Tersedia } 1 \text { atau } 2 \text { jenis elemen } \\
\text { buatan }\end{array}$ \\
\hline
\end{tabular}




\begin{tabular}{|c|c|c|c|c|c|c|}
\hline No & & Pernyataan & Kriteria Penilaian & Skor & Penilaian & Keterangan \\
\hline & & & Sangat tersedia & 3 & & Tersedia 3 atau 4 elemen buatan \\
\hline \multicolumn{7}{|c|}{ KUALITAS VISUAL } \\
\hline \multirow{6}{*}{4} & \multirow{6}{*}{ View } & \multirow{3}{*}{$\begin{array}{l}\text { Terdapat objek sebagai } \\
\text { orientasi view }\end{array}$} & Tidak tersedia & 1 & \multirow{4}{*}{3} & Tidak ada \\
\hline & & & Cukup tersedia & 2 & & Ada, namun kurang optimal \\
\hline & & & Sangat tersedia & 3 & & Ada dan sangat optimal \\
\hline & & \multirow{3}{*}{$\begin{array}{l}\text { View memberikan suatu kesan } \\
\text { (luas/terbuka) }\end{array}$} & Tidak tersedia & 1 & & Tidak ada \\
\hline & & & Cukup tersedia & 2 & 2 & Memberikan kesan cukup terbuka \\
\hline & & & Sangat tersedia & 3 & & Memberikan kesan luas/terbuka \\
\hline \multirow{4}{*}{5} & \multirow[t]{4}{*}{ Vista } & \multirow{3}{*}{$\begin{array}{l}\text { Tersedianya sebuah vista } \\
\text { (pembingkaian) }\end{array}$} & Tidak tersedia & 1 & & Tidak ada \\
\hline & & & Cukup tersedia & 2 & 1 & Ada, namun kurang optimal \\
\hline & & & Sangat tersedia & 3 & & Ada dan sangat optimal \\
\hline & & TOTAL & & & 14 & \\
\hline
\end{tabular}

Berdasarkan penilaian pada tabel 3 terlihat bahwa potensi visual yang terdapat pada view point 1 (Restaurant and Pool Area) termasuk dalam kategori tinggi, yaitu 14. Namun juga terlihat bahwa view yang ada belum dimanfaatkan secara optimal. Salah satu contohnya adalah view tersebut belum dimanfaatkan untuk membentuk sebuah vista.

Tabel 4. Penilaian View Point 2 (Beach Area)

\begin{tabular}{|c|c|c|c|c|c|c|}
\hline \multirow{2}{*}{\multicolumn{3}{|c|}{$\begin{array}{ll}\text { No } & \text { Pernyataan } \\
\text { KARAKTER VISUAL }\end{array}$}} & \multirow[t]{2}{*}{ Kriteria Penilaian } & \multirow[t]{2}{*}{ Skor } & \multirow{2}{*}{ Penilaian } & \multirow[t]{2}{*}{ Keterangan } \\
\hline & & & & & & \\
\hline & & & Tidak tersedia & 1 & & Tidak tersedia karakterstik alami \\
\hline \multirow[t]{2}{*}{1} & $\begin{array}{l}\text { Natural } \\
\text { Setting }\end{array}$ & $\begin{array}{l}\text { Tersedianya karaktersitik alami } \\
\text { seperti gunung/ laut/ pantai }\end{array}$ & Cukup tersedia & 2 & 3 & $\begin{array}{l}\text { Tersedia } 1 \text { atau } 2 \text { jenis karaktersitik } \\
\text { alami }\end{array}$ \\
\hline & & & Sangat tersedia & 3 & & Tersedia 3 jenis karakteristik alami \\
\hline \multirow{4}{*}{2} & & Tersedianya jenis tanaman & Tidak tersedia & 1 & & Tidak tersedia \\
\hline & Vegetation & $\begin{array}{l}\text { sebagai pembatas/pengarah } \\
\text { jalan/ pembentuk ruang }\end{array}$ & Cukup tersedia & 2 & 1 & $\begin{array}{l}\text { Tersedia } 1 \text { atau } 2 \text { jenis fungsi } \\
\text { tanaman }\end{array}$ \\
\hline & & & Sangat tersedia & 3 & & Tersedia 3 jenis fungsi tanaman \\
\hline & & Tersedianya elemen buatan & Tidak tersedia & 1 & & Tidak tersedia \\
\hline \multirow[t]{2}{*}{3} & $\begin{array}{c}\text { Manmade } \\
\text { element }\end{array}$ & $\begin{array}{l}\text { berbentuk fisik (sculpture/ } \\
\text { cottage/ water fountai/ gazebo }\end{array}$ & Cukup tersedia & 2 & 2 & $\begin{array}{l}\text { Tersedia } 1 \text { atau } 2 \text { jenis elemen } \\
\text { buatan }\end{array}$ \\
\hline & & & Sangat tersedia & 3 & & Tersedia 3 atau 4 elemen buatan \\
\hline \multicolumn{7}{|c|}{ KUALITAS VISUAL } \\
\hline \multirow{5}{*}{4} & & & Tidak tersedia & 1 & & Tidak ada \\
\hline & & orientasi view & $\begin{array}{l}\text { Cukup tersedia } \\
\text { Sanqat tersedia }\end{array}$ & $\begin{array}{l}2 \\
3\end{array}$ & 3 & $\begin{array}{l}\text { Ada, namun kurang optimal } \\
\text { Ada dan sangat optimal }\end{array}$ \\
\hline & View & & Tidak tersedia & 1 & & $\begin{array}{l}\text { Tidak ada } \\
\text { Tinal }\end{array}$ \\
\hline & & $\begin{array}{l}\text { View memberikan suatu kesan } \\
\text { (luas/terbuka) }\end{array}$ & Cukup tersedia & 2 & 3 & Memberikan kesan cukup terbuka \\
\hline & & & Sangat tersedia & 3 & & Memberikan kesan luas/terbuka \\
\hline \multirow{4}{*}{5} & Vista & Tersedianya sebuah vista & Tidak tersedia & 1 & & Tidak ada \\
\hline & & (pembingkaian) & Cukup tersedia & 2 & 2 & Ada, namun kurang optimal \\
\hline & & & Sangat tersedia & 3 & & Ada dan sangat optimal \\
\hline & & TOTAL & & & 14 & \\
\hline
\end{tabular}

Berdasarkan penilaian pada tabel 4 terlihat bahwa potensi visual yang terdapat pada view point 2 (Beach Area) termasuk dalam kategori tinggi, yaitu 14. Namun perlu adanya penyempurnaan dengan cara pembentukan vista dari tatanan vegetasi yang membentuk sebuah frame untuk meningkatkan kualitas visual serta penggunaan manmade element untuk meningkatkan karakter visual, sehingga ruang yang tercipta di sepanjang pantai juga dapat dimanfaatkan oleh pengunjung untuk beraktivitas sambil menikmati potensi visual yang ada.
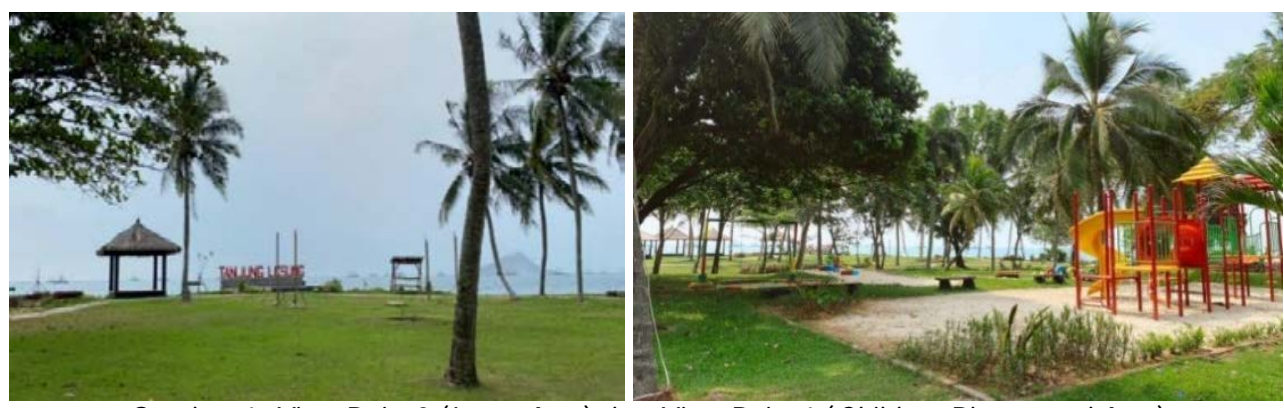

Gambar 4. View Point 3 (Lawn Area) dan View Point 4 (Children Playground Area) Sumber: Dokumen Pribadi Penelti, 2021 
View point 3 (lawn area) berada di zona rekreasi yang menghadap secara langsung ke arah gunung krakatau, sedangkan view point 4 (children playground area) berada di zona cottage yang merupakan tempat bermain anak. Berdasarkan potensi visual yang ada dilakukan penilaian visual lanskap pada view point 3 dan view point 4 yang dapat dilihat pada tabel 5 dan tabel 6 .

Tabel 5. Penilaian View Point 3 (Lawn Area)

\begin{tabular}{|c|c|c|c|c|c|c|}
\hline \multirow{2}{*}{\multicolumn{3}{|c|}{$\begin{array}{lr}\text { No } & \text { Pernyataan } \\
\text { KARAKTER VISUAL }\end{array}$}} & \multirow[t]{2}{*}{ Kriteria Penilaian } & \multirow[t]{2}{*}{ Skor } & \multirow[t]{2}{*}{ Penilaian } & \multirow[t]{2}{*}{ Keterangan } \\
\hline & & & & & & \\
\hline \multirow{3}{*}{1} & & & Tidak tersedia & 1 & \multirow{3}{*}{3} & Tidak tersedia karakterstik alami \\
\hline & $\begin{array}{l}\text { Natural } \\
\text { Setting }\end{array}$ & $\begin{array}{l}\text { Tersedianya karaktersitik alami } \\
\text { seperti gunung/ laut/ pantai }\end{array}$ & Cukup tersedia & 2 & & $\begin{array}{l}\text { Tersedia } 1 \text { atau } 2 \text { jenis karaktersitik } \\
\text { alami }\end{array}$ \\
\hline & & & Sangat tersedia & 3 & & Tersedia 3 jenis karakteristik alami \\
\hline \multirow{3}{*}{2} & & Tersedianya jenis tanaman & Tidak tersedia & 1 & \multirow{3}{*}{2} & Tidak tersedia \\
\hline & Vegetation & sebagai pembatas/pengarah & Cukup tersedia & 2 & & Tersedia 1 atau 2 jenis fungsi tanaman \\
\hline & & jalan/ pembentuk ruang & Sangat tersedia & 3 & & Tersedia 3 jenis fungsi tanaman \\
\hline \multirow{3}{*}{3} & & Tersedianya elemen buatan & Tidak tersedia & 1 & \multirow{3}{*}{2} & Tidak tersedia \\
\hline & Manmade & berbentuk fisik (sculpture/ & Cukup tersedia & 2 & & Tersedia 1 atau 2 jenis elemen buatan \\
\hline & element & cottage/ water fountai/ gazebo & Sangat tersedia & 3 & & Tersedia 3 atau 4 elemen buatan \\
\hline \multicolumn{7}{|c|}{ KUALITAS VISUAL } \\
\hline \multirow{6}{*}{4} & \multirow{6}{*}{ View } & \multirow{3}{*}{$\begin{array}{l}\text { Terdapat objek sebagai } \\
\text { orientasi view }\end{array}$} & Tidak tersedia & 1 & \multirow{4}{*}{3} & Tidak ada \\
\hline & & & Cukup tersedia & 2 & & Ada, namun kurang optimal \\
\hline & & & Sangat tersedia & 3 & & Ada dan sangat optimal \\
\hline & & \multirow{3}{*}{$\begin{array}{l}\text { View memberikan suatu kesan } \\
\text { (luas/terbuka) }\end{array}$} & Tidak tersedia & 1 & & Tidak ada \\
\hline & & & Cukup tersedia & 2 & \multirow[t]{2}{*}{3} & Memberikan kesan cukup terbuka \\
\hline & & & Sangat tersedia & 3 & & Memberikan kesan luas/terbuka \\
\hline \multirow{4}{*}{5} & Vista & Tersedianya sebuah vista & Tidak tersedia & 1 & \multirow{3}{*}{2} & Tidak ada \\
\hline & & pembingkai & Cukup tersedia & 2 & & Ada, namun kurang optimal \\
\hline & & & Sangat tersedia & 3 & & Ada dan sangat optimal \\
\hline & & TOTAL & & & 15 & \\
\hline
\end{tabular}

Berdasarkan penilaian pada tabel 5 terlihat bahwa potensi visual yang terdapat pada view point 3 (Lawn Area) termasuk dalam kategori tinggi, yaitu 15. Namun perlu adanya penyempurnaan seperti pembentukan vista dari tatanan vegetasi yang membentuk sebuah frame untuk meningkatkan kualitas visual serta penggunaan manmade element untuk meningkatkan karakter visual, sehingga ruang yang tercipta di area berumput juga dapat dimanfaatkan oleh pengunjung untuk beraktivitas sambil menikmati potensi visual yang ada.

Tabel 6. Penilaian View Point 4 (Children Playground Area)

\begin{tabular}{|c|c|c|c|c|c|c|}
\hline No & & Pernyataan & Kriteria Penilaian & Skor & Penilaian & Keterangan \\
\hline & AKTER VIS & $\overline{\mathrm{JAL}}$ & & & & \\
\hline & & & Tidak tersedia & 1 & & Tidak tersedia karakterstik alami \\
\hline 1 & $\begin{array}{l}\text { Natural } \\
\text { Setting }\end{array}$ & $\begin{array}{l}\text { Tersedianya karaktersitik alami } \\
\text { seperti gunung/ laut/ pantai }\end{array}$ & Cukup tersedia & 2 & 2 & $\begin{array}{l}\text { Tersedia } 1 \text { atau } 2 \text { jenis karaktersitik } \\
\text { alami }\end{array}$ \\
\hline & & & Sangat tersedia & 3 & & Tersedia 3 jenis karakteristik alami \\
\hline & & Tersedianya jenis tanaman & Tidak tersedia & 1 & & Tidak tersedia \\
\hline 2 & Vegetation & $\begin{array}{l}\text { sebagai pembatas/pengarah } \\
\text { jalan/ pembentuk ruang }\end{array}$ & Cukup tersedia & 2 & 2 & $\begin{array}{l}\text { Tersedia } 1 \text { atau } 2 \text { jenis fungsi } \\
\text { tanaman }\end{array}$ \\
\hline & & & Sangat tersedia & 3 & & Tersedia 3 jenis fungsi tanaman \\
\hline & & Tersedianya elemen buatan & Tidak tersedia & 1 & & Tidak tersedia \\
\hline 3 & $\begin{array}{l}\text { Manmade } \\
\text { element }\end{array}$ & $\begin{array}{l}\text { berbentuk fisik (sculpture/ } \\
\text { cottage/ water fountai/ gazebo }\end{array}$ & Cukup tersedia & 2 & 2 & $\begin{array}{l}\text { Tersedia } 1 \text { atau } 2 \text { jenis elemen } \\
\text { buatan }\end{array}$ \\
\hline & & & Sangat tersedia & 3 & & Tersedia 3 atau 4 elemen buatan \\
\hline & ALITAS VISL & & & & & \\
\hline & & & Tidak tersedia & 1 & & Tidak ada \\
\hline & & I erdapal odjek sedagal & Cukup tersedia & 2 & 2 & Ada, namun kurang optimal \\
\hline 4 & Уiew & orlentasi view & Sangat tersedia & 3 & & Ada dan sangat optimal \\
\hline 4 & VIew & & Tidak tersedia & 1 & & Tidak ada \\
\hline & & $\begin{array}{l}\text { View memperikan suatu kesan } \\
\text { (luas/terbuka) }\end{array}$ & Cukup tersedia & 2 & 1 & Memberikan kesan cukup terbuka \\
\hline & & & Sangat tersedia & 3 & & Memberikan kesan luas/terbuka \\
\hline & Vista & Tersedianya sebuah vista & Tidak tersedia & 1 & & Tidak ada \\
\hline 5 & & pembingkai & Cukup tersedia & 2 & 1 & Ada, namun kurang optimal \\
\hline & & & Sangat tersedia & 3 & & Ada dan sangat optimal \\
\hline
\end{tabular}


Berdasarkan penilaian pada tabel 6 terlihat bahwa potensi visual yang terdapat pada view point 4 (Children Play Ground Area) termasuk dalam kategori sedang, yaitu 10. Pada beberapa bagian dari area dapat memanfaakan visual yang ada dengan memberikan sentuhan berupa pembentukan vista melalui tatanan vegetasi atau menciptakan manmade element yang fungsional dan menambah keindahan visual.
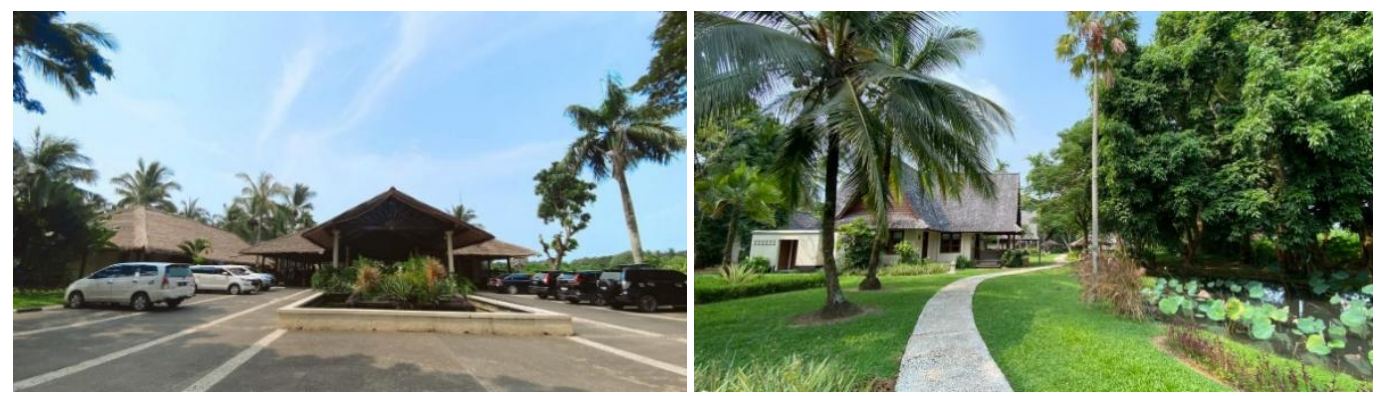

Gambar 5. View Point 5 (Welcome Area) dan View Point 6 (Cottage Area) Sumber: Dokumen Pribadi Peneliti, 2021

View point 5 (welcome area) berada di zona penerima, yaitu area keluar masuk kendaran dan pengguna tapak, sedangkan view point 6 (cottage area) berada di zona cottaga yang merupakan area penginapan bagi pengunjung resort. Untuk meningkatkan karakter visual dan kualitas visual dilakukanlah penilaian visual lanskap pada view point 5 dan view point 6 yang dapat di lihat pada tabel 7 dan tabel 8 .

Tabel 7. Penilaian View Point 5 (Welcome Area)

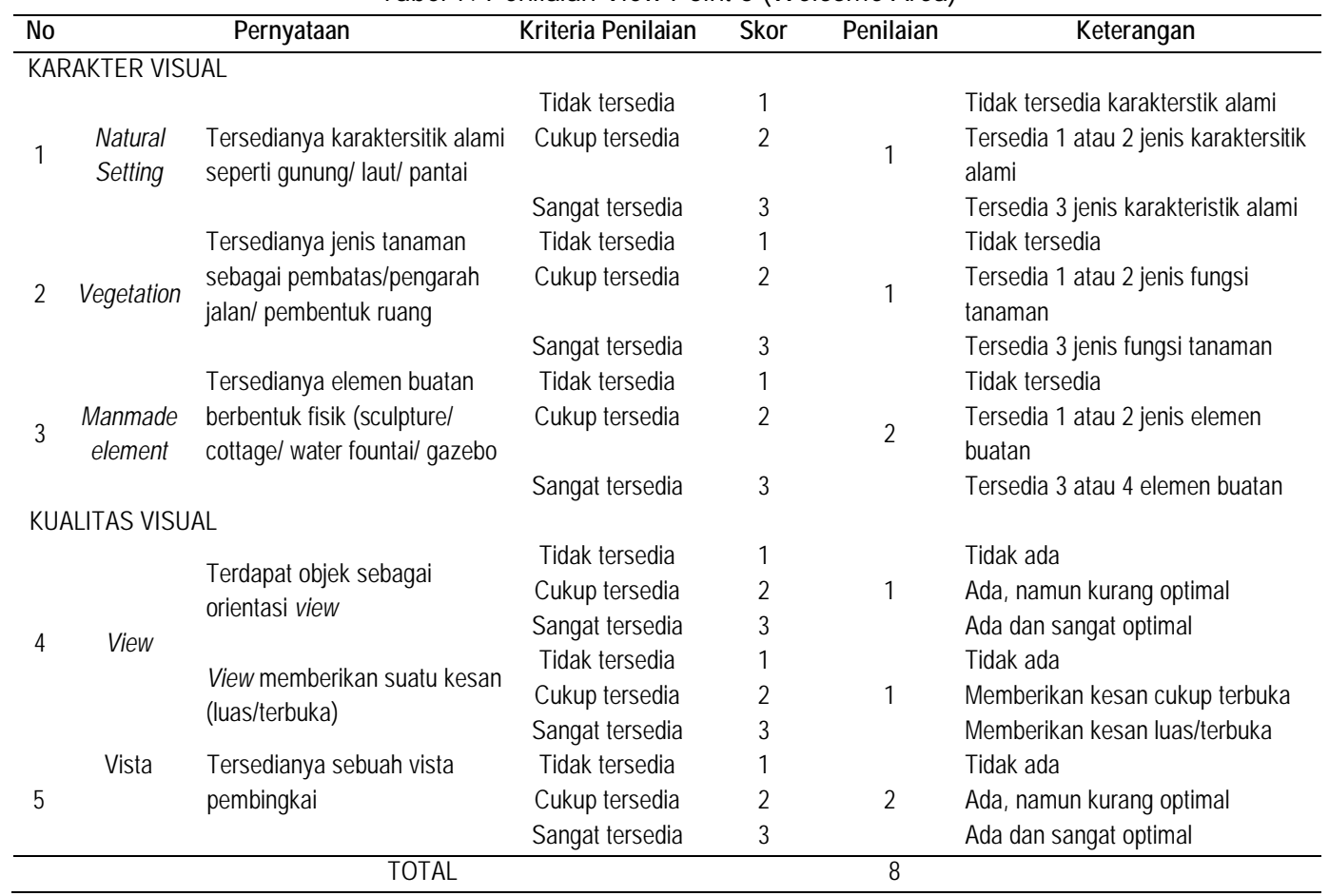

Berdasarkan penilaian pada tabel 7 terlihat bahwa potensi visual yang terdapat pada view point 5 (Welcome area) termasuk dalam kategori rendah, yaitu 8. Pada area ini tidak terdapat potensi visual yang cukup baik untuk dimanfaatkan, tapi kualitas visual yang ada dapat ditingkatkan dengan cara memberikan penataan pola hijau dan pengadaan view melalui penempatan elemen-elemen lansap dengan mempertimbangkan fungsi dan keindahan visual. 
Tabel 8. Penilaian View Point 6 (Cottage Area)

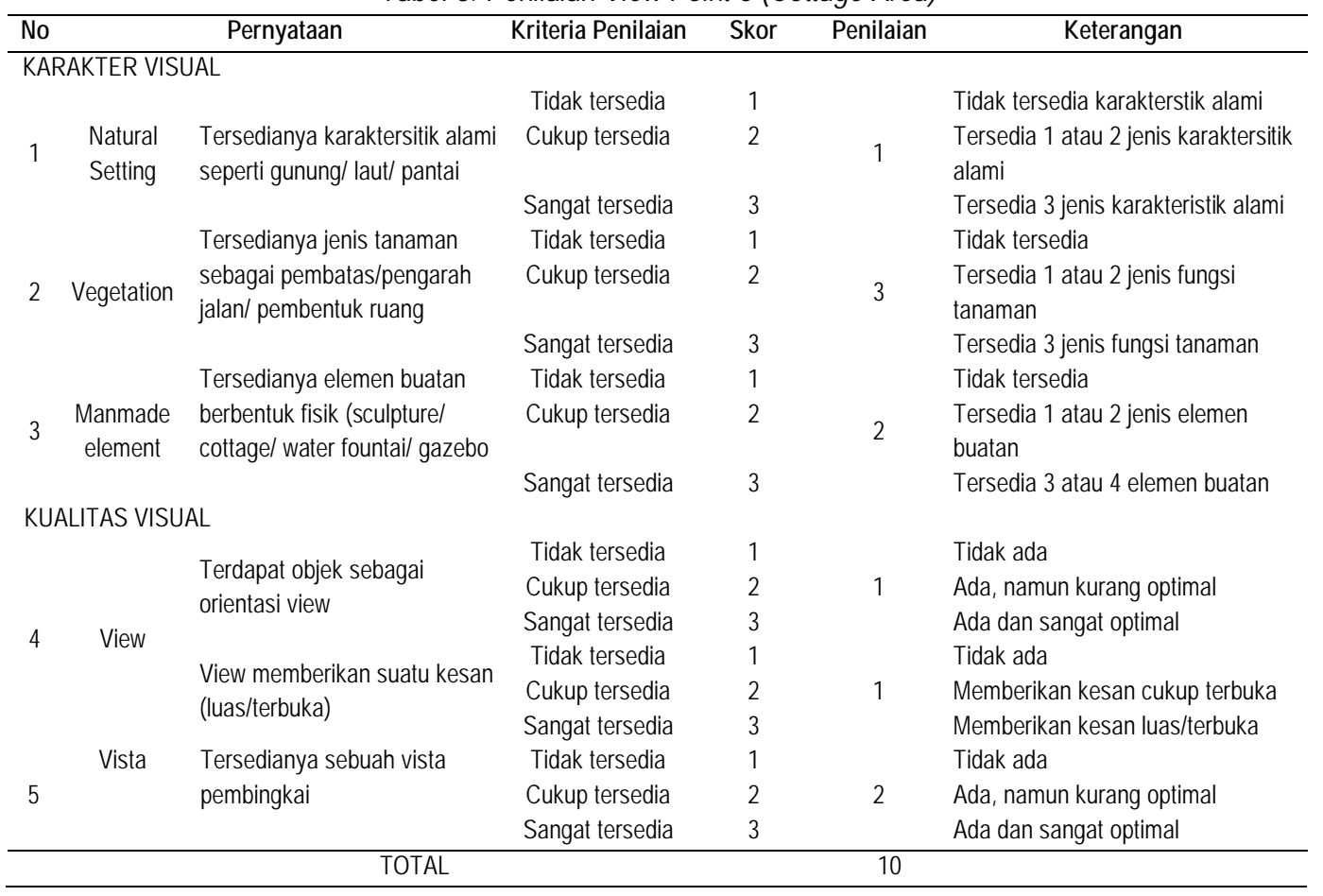

Berdasarkan penilaian pada tabel 8 terlihat bahwa potensi visual yang terdapat pada view point 6 (Cottage Area) termasuk dalam kategori sedang, yaitu 10. Pada area ini potensi visual berupa view banyak yang tertutup oleh komposisi bangunan. Namun dapat dilakukan penataan pola hijau dan pengadaan view melalui penempatan elemen-elemen lanskap dengan lebih baik dengan tetap mempertimbangkan fungsi dan keindahan visual.

Berdasarkan penilaian visual yang telah dilakukan, klasifikasi titik view point ke dalam kualitas visual tinggi, sedang dan rendah dapat dilakukan dan dipetakan dalam masterplan The Bay Villas Resort (Gambar 6 dan 7). Hasil klasifikasi visual menunjukan bahwa view point 1 (Restaurant dan Pool area), view point 3 (Lawn Area), dan view point 3 (Beach Area) merupakan klasifikasi visual tinggi yang ditandai oleh warna biru. View point 4 (Children Playground Area) dan view point 6 (Cottage Area) merupakan klasifikasi visual sedang yang ditandai oleh warna ungu. View point 5 (Welcome Area) merupakan klasifikasi visual rendah yang ditandai oleh warna kuning. Lanskap yang paling tinggi kualitas visual nya berada di area yang memiliki pemandangan kearah gunung krakatau, berada di zona rekreasi yang merupakan area pantai dengan total quality 15 . Sebaliknya kualitas visual yang rendah berada di area yang kurang tertata dan tidak langsung menghadap gunung krakatau, berada di zona penerima dengan total quality 8 . 


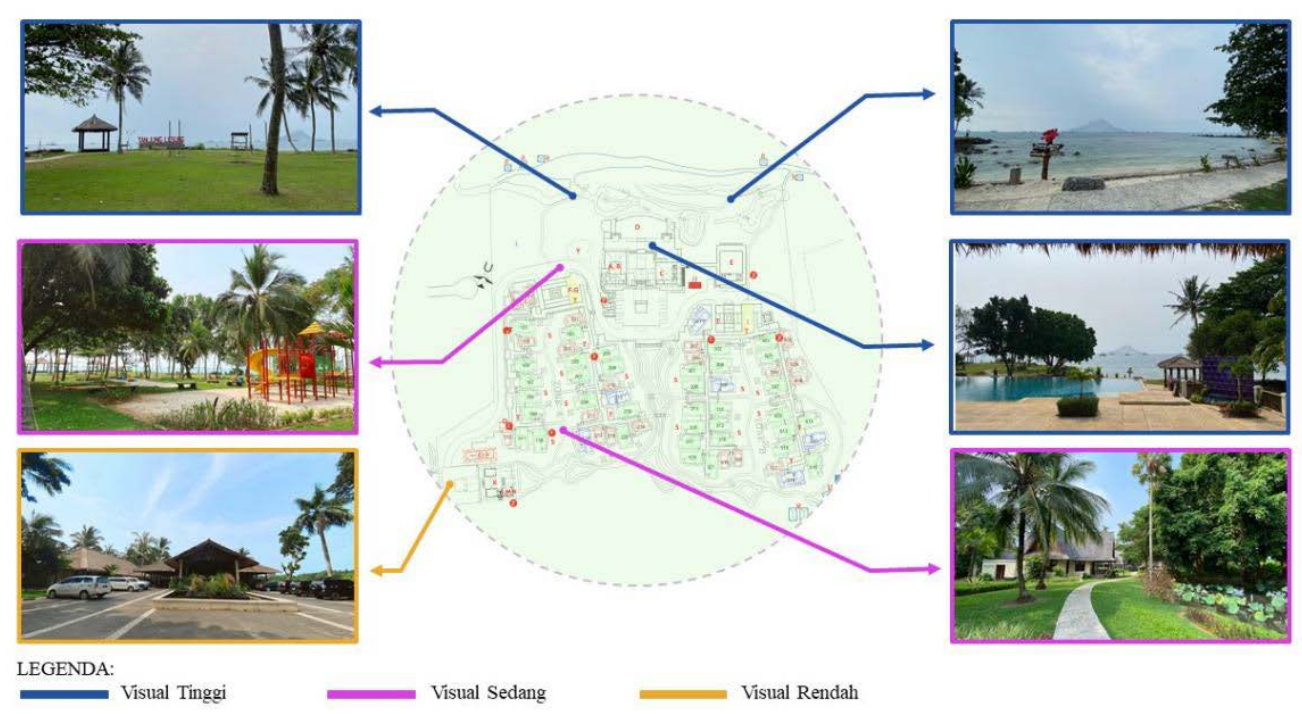

Gambar 6. Hasil Klasifikasi Visual pada Masterplan The Bay Villas Resort Sumber: Dokumen Pribadi Peneliti, 2021

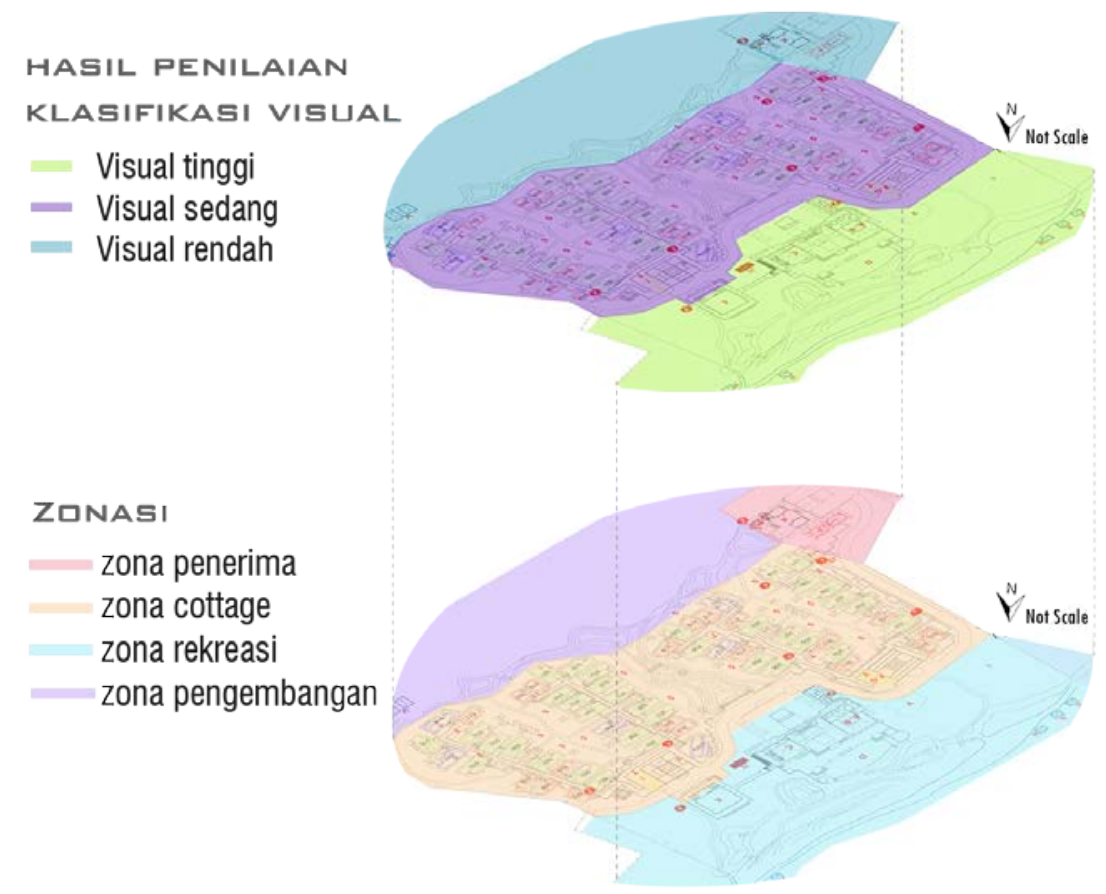

Gambar 7. Klasifikasi visual pada master plan Sumber: Dokumen Pribadi Peneliti, 2021

Berdasarkan hasil penilaian kualitas visual lanskap yang dapat diterapkan pada masterplan kawasan dapat dilihat bahwa Zona Penerima termasuk kedalam klasifikasi visual rendah berada di area yang tidak secara langsung menghadap ke arah gunung krakatau. Zona Cottage termasuk kedalam klasifikasi visual sedang. Zona Rekreasi termasuk kedalam klasifikasi visual tinggi berada di area yang memiliki pemandangan kearah gunung krakatau. Kualitas visual yang tinggi berada di zona rekreasi pantai sehingga 
pada zona ini lah diperlukan perancangan fasilitas rekreasi yang optimal agar pengunjung dapat menikmati view yang tersedia.

\section{Simpulan}

Berdasarkan penilaian kualitas visual melalui metode penilaian deskriptif, visual lanskap yang paling tinggi kualitas visual nya berada di area yang memiliki pemandangan kearah gunung krakatau dan berada di zona rekreasi yang merupakan area pantai dengan total nilai 15. Sebaliknya kualitas visual yang rendah berada di area yang kurang tertata dan tidak langsung menghadap gunung Krakatau, yaitu di zona penerima dengan total nilai 8. Hasil penilaian ini dapat dimanfaatkan untuk pengembangan rancangan lanskap selanjutnya. Zona dengan kualitas visual tinggi dapat dikembangkan dengan berbagai fasilitas rekreasi seperti sitting area, promenade, lawn, dan outdoor cafe sebagai wadah kegiatan pengunjung yang bersifat pasif dan diutamakan untuk menikmati pemandangan yang ada. Untuk zona dengan kualitas visual sedang dan rendah dapat dimanfaatkan untuk fasilitas rekreasi aktif seperti fasilitas bermain anak, cottage, krakatau pool, taman, dan fasilitas olahraga. Dengan demikian, peningkatan daya tarik pada The Bay Villas Resort melalui visual lanskap dapat tercapai.

\section{Daftar Pustaka}

Budiyono, D., \& Soelistyari, H. T. (2016). Evaluasi Kualitas Visual Lanskap Wisata Pantai Balekambang Di Desa Srigonco, Kabupaten Malang. Jurnal Lanskap Indonesia, 8(2), 80-90.

Firmansyah. (2011). Metode Assessment Deskriptif Kualitas Visual Lanskap Kampus di Indonesia, Kasus Studi: Lanskap Kampus ITB. Jurnal Tata Loka, 13(3), 1-14.

Krisantia, I., \& Rabindra, I. B. (2014). Model Penilaian Lanskap Visual Untuk Melestarikan Pemandangan pada Tujuan Wisaata Anyer Puncak Bandung Jawa Barat. Pada Tujuan Wisaata Anyer Puncak Bandung Jawa Barat, 4(1), 1-8.

Motloch, J. (1991). Introduction to Landscape Design. New York: Van Nostrand Reinhold.

Smardon, R. C. (1988). Visual Resources Assessment Procedure. New York: Syarcuse. 